Author version: Environ. Monit. Assess., vol.186; 2014; 4129-4137

\title{
Monitoring ocean surface algal blooms in coastal and oceanic waters around
}

\section{India}

\author{
Muniyandi Tholkapiyan ${ }^{1}$, Palanisamy Shanmugam ${ }^{1}$, T. Suresh ${ }^{2}$ \\ ${ }^{1}$ Ocean Optics and Imaging Laboratory, Department of Ocean Engineering, Indian Institute of \\ Technology Madras, Chennai - 600036, India \\ ${ }^{2}$ National Institute of Oceanography, Goa - 403004, India \\ *Corresponding author: Dr. P. Shanmugam, Phone: 91-44-22574818, Email: \\ pshanmugam@iitm.ac.in
}

\begin{abstract}
The National Aeronautics and Space Administration's (NASA) sensor MODIS-Aqua provides an important tool for reliable observations of the changing ocean surface algal bloom paradigms in coastal and oceanic waters around India. A time series of the MODIS-Aqua derived OSABI (ocean surface algal bloom index) and its seasonal composite images report new information and comprehensive pictures of these blooms and their evolution stages in a wide variety of events occurred at different times of the years from 2003-2011, providing the first large area survey of such phenomena around India. For most of the years, the results show a strong seasonal pattern of surface algal blooms elucidated by certain physical and meteorological conditions. The extent of these blooms reaches a maximum in winter (November-February) and a minimum in summer (JuneSeptember), especially in the northern Arabian Sea. Their spatial distribution and retention period are also significantly increased in the recent years. The increased spatial distribution and intensity of these blooms in the northern Arabian Sea in winter are likely caused by enhanced cooling, increased convective mixing, favorable winds and atmospheric deposition of the mineral aerosols (from surrounding deserts) of the post-southwest monsoon period. The southward Oman coastal current and southwestward winds become apparently responsible for their extension upto the central Arabian Sea. Strong upwelling along this coast further triggers their initiation and growth. Though there is a warming condition associated with increased sea surface height anomalies along the coasts of India and Sri Lanka in winter, surface algal bloom patches are still persistent along these coasts due to northeast monsoonal winds, enhanced precipitation and subsequent nutrient enrichment in these areas. The occurrence of the surface algal blooms in the northern Bay of Bengal coincides with a region of the well-known Ganges-Brahmaputra Estuarine Frontal (GBEF) system, which increases supply of nutrients in addition to the land-derived inputs triggering surface algal blooms in this region. Low density (initiation stage) of such blooms observed in clear oceanic waters southeast and northeast of Sri Lanka may be caused by the vertical mixing processes (strong monsoonal winds) and the occurrence of Indian Ocean Dipole events. Findings based on the analyses of time series satellite data indicate that the new information on surface algal blooms will have important bearing on regional fisheries, ecosystem and environmental studies, and implications of climate change scenarios.
\end{abstract}

Keywords: Climate change, Hydrographic change, Nutrients, Surface algal blooms, Remote sensing, MODIS-Aqua. 


\section{Introduction}

Over the past decades, many studies have focused on deriving concentrations of chlorophyll-a using certain empirical algorithms to detect and describe the spatial and temporal distributions of phytoplankton biomass in coastal and oceanic waters (Vinayachandran and Mathew 2003, Vinayachandran et al 2003, Goes et al 2005, Ahn and Shanmugam 2007, Gomes et al., 2008, Prasanna Kumar et al 2010, Li et al 2011). Chlorophyll-a estimations are based on the reflectance (or radiance) ratio algorithms that take advantage of decreased reflectance in the blue (440-510nm) and increased reflectance in the green (500-565nm) by working in terms of the ratios in these two wavelength domains, although being erroneously retrieved by these algorithms in optically more complex waters (Shanmugam 2011). However, these studies have been dedicated to analyze the pigment distribution (indicative of both surface and in-water algal blooms) and its relation with dynamic oceanographic and meteorological conditions. On the other hand, ocean surface (floating) algal blooms that have been reported in the literature (Sarangi et al 2004, Shanmugam et al 2013) and in various local news papers and media still remain largely unexplored due to the difficulty with ship-borne measurements. In fact, satellite estimation of such blooms is the most difficult task due to atmospheric correction problems (Shanmugam et al 2013).

Some of the surface algal blooms are known to play a critical role in determining ocean productivity and carbon flux (Takeuchi 2013), while others can cause significant adverse impact on local environments and economy (Hu 2009, Steckbauer et al 2011). Thus, it is extremely important to better understand the occurrence, location, extent, intensity, and seasonal and interannual variability of these blooms to draw conclusions about water body's health, composition, ecological status and coastal management strategy. However, the spectral signature of surface algal blooms is very different from those of other water features (e.g., suspended sediments and in-water algal blooms) because of a sharp rise in radiances (or reflectances) between 670 and 780nm (due to increased pigment contents similar to land vegetation). This imposes major constraints on the use of the present atmospheric correction algorithms to retrieve surface-leaving radiances (due to floating blooms) from satellite ocean color data, which limits the study of the spectral characterization of these blooms in coastal and oceanic waters. More recently, Shanmugam et al (2013) developed a technique (hereafter referred as "OSABT") that combines a complex water atmospheric correction algorithm and ocean surface algal bloom index (OSABI) to provide essential data for detection and optical spectral characterization of surface algal blooms in coastal and open ocean waters. This technique was applied to several MODIS-Aqua imageries from Arabian Sea and other regional waters and its 
results were systematically studied with regard to the spectral characteristics of several surface algal blooms, their evolution stages, sub-pixel variability, and atmospheric correction issues.

The MODIS-Aqua instrument (2002-present) is equipped with several narrow spectral bands (with spatial resolution of $1.1 \times 1.1 \mathrm{~km}$ at nadir) with a swath width of $2300 \mathrm{~km}$, providing high temporal data having great potential for mapping of surface algal blooms. Due to the lack of reliable algorithms no previous studies have examined their characteristics and dynamics in oceanic waters around India. In this paper, we show the validity of OSABT in two different bloom regions, and apply this technique to a time-series MODIS-Aqua data to study the surface algal bloom events and their location, extent, intensity, and seasonal and interannual variability in conjugation with various physical oceanographic and metrological data.

\section{Data and Methods}

Ship-borne radiometric and water sampling measurements were conducted in bloom dominated waters (Noctiluca scintillans) of the Arabian Sea during February 2009. The ship intersected a dense bloom of this dinoflagellate on 17 February 2009 at $11-14$ hours at a location $20.96^{\circ} \mathrm{N}$ and $66.17^{\circ} \mathrm{E}$ off Gujarat Coast and necessary measurements were made subsequently. Similar measurements were performed with the Trios radiometers (both the above and underwater measurements in the spectral range of $350-1050 \mathrm{~nm})$ in lagoon waters $\left(12^{\circ} 48^{\prime} 14.13^{\prime \prime} \mathrm{N}\right.$; 80²14'24.05"E) on the southeast coast of India, dominated by a thick green bloom during 2 May 2013.

Ocean color images (Level 1A) acquired by MODIS-Aqua over the Arabian Sea, Indian Ocean and Bay of Bengal from 2003-2011 were obtained from the NASA Goddard Space Flight Centre (http://oceancolor.gsfc.nasa.gov/). Scenes severally contaminated by clouds and extreme atmospheric conditions were discarded from the analysis. The remaining time-series MODIS-Aqua data were processed using the OSABT technique (Shanmugam et al., 2013) to derive ocean surface algal bloom indices (OSABI) for depicting the surface bloom events and their evolution stages. These data were analysed in conjugation with time-series and seasonal images of sea surface temperature (SST) (http://gdata1.sci.gsfc.nasa.gov), surface wind (National Climatic Data Center, NOAA), sea surface height anomaly (SSHA) with geostrophic currents (AVISO) and aerosol index data (http://gdata1.sci.gsfc.nasa.gov/daac-bin/G3/gui.cgi?instance_id=toms,

http://gdata1.sci.gsfc.nasa.gov/daac-bin/G3/gui.cgi?instance_id=omi) obtained from various resources and processed for this study. 
The difference between the ocean surface algal blooms (as described by OSABI values) and traditional satellite chlorophyll is that Chlorophyll is widely used as an index of overall phytoplankton biomass in a given location, and is generally estimated from satellite data using traditional blue-green ratio algorithms. Since these is no changes in the spectral radiance or reflectance spectra in the blue-green spectral region, these algorithms estimating chlorophyll concentration cannot distinguish pixels with in-water blooms and surface algal blooms. By contrast, the OSABT takes advantage of the red-NIR radiances to distinguish pixels with in-water and surface algal blooms. Most surface algal blooms exhibit high radiances in the NIR region, whereas most inwater algal blooms show a peak in the red region (at 678nm in case of MODIS-Aqua). Thus, OSABT products derived from MODIS-Aqua would be more useful than traditional chlorophyll products derived from such satellite ocean color data.

\section{Results and Discussion}

Oceanic waters around India are influenced by seasonally reversing monsoonal wind forcing, which makes this region exceptional among the world oceans. Figure 1 shows major currents in coastal and oceanic waters around India during winter and summer. Notably, the coastal currents along the west and east coasts of India provide a link between the Arabian Sea (AS) and Bay of Bengal (BOB) which show opposing trends in surface circulation during summer (SW) and winter (NE) monsoons. Due to this these regions establish the differences in hydrological condition. The Arabian Sea is characterized by a peculiar thermohaline structure and circulation (Olson, 1992; Morrison et al., 1998) with the semi-annual reversal of surface currents associated with the monsoon, water mass intrusions from marginal seas, and the absence of subtropical convergence or deepwater formation due to the Asian landmass. During summer the eastward flowing SMC carries saltier Arabian Sea high salinity waters into the BOB, while during winter both the northwestward flowing WICC and southward flowing EICC transport warm and low-salinity waters from BOB into the AS. Because of the hydrographic differences and reversal wind patterns between the AS and BOB, there is a contradictable occurrence of surface algal blooms in coastal and oceanic waters on the west and east coasts of India.

Figure 2a is a weekly composite OSABI image derived from MODIS-Aqua (16-21 Feb. 2009) using the OSABT technique. It clearly demonstrates dense surface bloom patches originating from coastal waters of Somalia, Oman and eastern AS. On 17 February 2009, we encountered these bloom patches (green color as shown in the field photo) in offshore waters of Gujarat (west coast) represented by dense Noctiluca blooms. At this location, Secchi depth was reduced to $2.46 \mathrm{~m}$ by a 
thick surface bloom showing the exponentially decreasing chlorophyll concentration with the increasing depth (27.7 to $3 \mu \mathrm{g} \mathrm{L}^{-1}$ from surface to $33 \mathrm{~m}$, see the insert on Fig. 2a). This bloom is a common phenomenon in the Arabian Sea during winter. The normalized surface-leaving radiance measured (in-situ) from this bloom shows the presence of a red edge with the radiance increase extending to the wavelength of 748nm (and longer), with a maximum value exceeding $1 \mathrm{~mW} \mathrm{~cm}^{-2}$ $\mu \mathrm{m}^{-1} \mathrm{sr}^{-1}$ at this wavelength and a little difference in the visible wavelengths. This is an indication of the maturity stage of the bloom typical of land vegetation (see OSABI >10) (Shanmugam et al 2013). However, the MODIS-derived $\mathrm{nL}_{\mathrm{w}}$ spectrum did not exhibit similar spectral signature because of the sub-pixel problem (meaning that the observed bloom patches were in terms of few meters in size, while MODIS-Aqua $1.1 \times 1.1 \mathrm{~km}$ pixel covered the large water fraction and low bloom fraction) (more information in Shanmugam et al 2013).

To further examine the intensity of such dense surface algal blooms, surface-leaving radiances and upwelling radiances (just below the water surface) measured in highly dense bloom waters of the lagoon on the southeast coast of India were also examined. As shown in Fig. 2b, the radiance spectra (top) of these blooms are characteristically similar to that observed in the AS, although showing much higher values in the NIR and visible wavelengths because of the increased chlorophyll concentrations (245-897 $\mathrm{mg} \mathrm{m}^{-3}$ ). As a consequence, much of the visible light radiance is vanished in the underwater radiometric measurements (see upwelling radiance spectra $\mathrm{L}_{\mathrm{u}}$ ) and only the NIR signal emerges out due to the red-shift effects. Nevertheless, surface-leaving radiance spectra collected in these waters conform to established descriptions of red-shifts denoting changes to longer wavelengths in correlation to changes in chlorophyll concentrations (Shanmugam et al 2013).

Since this is the first study of detecting and systematically describing the surface algal bloom distribution and its seasonal and interannual variations, we obtained time series MODIS-Aqua data for the years 2003-2011 and processed using the OSABT technique to analyse its distribution and evolution stages (into initiation stage, development stage and maturity stage relative to MODIS pixel resolution), which resulted in a wide variety of bloom events at different times of the year and provided the first large area survey of surface algal blooms in oceanic waters around India. Figure 3 shows the spatial distributions of surface algal blooms detected by MODIS-Aqua for two seasons summer (June-September) (left panels) and winter (November-February) (right panels). These seasonal composite images were obtained for the period 2003-2011 (by accounting the average OSABI values of every four months corresponding to summer and winter monsoons - JuneSeptember and November-February respectively), which demonstrate that these surface algal blooms 
are aggregated into patches and long lines by surface currents and eddies, convergence and shear. The aerial coverage (extent) of these blooms reaches a maximum in winter and a minimum in summer. Large distributions and intensities of these blooms are well confined within the regions of the Gulf of Oman and central Arabian Sea, because of the enhanced cooling under favorable winds and increased convective mixing which lead to the supply of subsurface nutrients to the euphotic zone already enriched with the mineral aerosols (due to atmospheric deposition) of the postsouthwest monsoon (a factor for regulating the phytoplankton growth). The southward Oman coastal current and southwestward winds are responsible for their extension upto the central Arabian Sea. Recurrent upwelling events along this coast also trigger the development of massive surface algal blooms. These findings are supported by the time series profiles and seasonal images of SSH, geostrophic currents, SST and aerosols (Figs. 3 and 4). These data apparently indicate that frequent and dense surface algal blooms in the northern Arabian Sea occur due to the combination of several physical oceanographic and meteorological factors. Though there is a warming condition with increased SSH anomalies along the east coast of India, high distributions of surface algal blooms are also observed due to the northeast monsoonal winds and enhanced precipitation which enriches these coastal waters with high levels of nutrients Interestingly, large patches of low density surface algal blooms are seen around the entire Sri Lankan Island in both summer and winter seasons and are often associated with the boundaries of divergence (upwelling/cyclonic eddies in summer) and convergence (anticyclonic eddies in winter) and the intense monsoonal winds (Fig. 4, bottom panels). The occurrence of surface algal blooms in the northern Bay of Bengal coincides with a region of the well-known Ganges-Brahmaputra Estuarine Frontal (GBEF) system, which increases supply of nutrients in addition to the land-derived inputs triggering surface algal blooms in this region. Low density patches of such blooms are also observed in clear oceanic waters southeast of Sri Lanka (summer) and northeast of Sri Lanka (winter), possibly caused by the occurrence of the Indian Ocean Dipole events and vertical mixing caused by storm events. Overall, our analysis indicates that the mean seasonal distributions of the surface algal blooms in the entire region during summer (2003 to 2011) had an area of 1,67,640 $\mathrm{Km}^{2}$ (initial stage), 11,125 $\mathrm{Km}^{2}$ (development stage) and $8,443 \mathrm{Km}^{2}$ (maturity stage). Note that there is an abrupt increase in the aerial coverage and distribution of the surface algal blooms during winter (Fig. 3), with the initiation, development and maturity stages of the blooms being 8,59,692 $\mathrm{Km}^{2}, 2,84,602 \mathrm{Km}^{2}$ and 1,25,560 $\mathrm{Km}^{2}$ respectively.

Further, a time series of the MODIS-Aqua derived OSABI (2003-2011) shows that the aerial coverage of all three stages of surface algal blooms in coastal and oceanic waters around India is amplified in winter than in summer, although the initiation stage of these blooms showing an 
increasing trend as compared to the development and maturity stages. For all the years, they attain a peak in the month of February which is especially increased to over $40000 \mathrm{~km}^{2}$ in 2008. The estimated total area of surface algal blooms is apparently increasing in the recent years (from 2008 to 2011) and this trend is consistent with the SSHA and aerosol index time series data, although there are no remarkable changes in the SST and SSW patterns (Fig. 3). The time series MODIS-Aqua OSABI profile also shows an increase in the retention period and aerial coverage of surface algal blooms in the years 2008-2011, shifting from November-March to September-April. This trend raises the possibility that the recent changes in circulation patterns, sea level rise and atmospheric deposition (desert mineral aerosols) along with favorable meteorological conditions are making the Arabian Sea more vulnerable or productive, thereby drawing attention of coastal managers, fishing community, scientists, and governmental bodies towards improving and developing management and amelioration strategies.

\section{Conclusion}

The time series OSABI products derived from MODIS-Aqua data (from 2003-2011) provided new and comprehensive information concerning surface algal blooms in coastal and oceanic waters around India. Though this study is not specific to certain blooms, there are already reported surface algal blooms including Trichodesmium erythraeum (Arabian Sea, Coastal waters of Bay of Bengal), Trichodesmium thiebautii (Arabian Sea, Coastal waters of Bay of Bengal), Noctiluca scintillans / Noctiluca miliaris (Arabian Sea, Coastal waters of Bay of Bengal), and Cochlodinium polykrikoides (along the coast of Oman, Arabian Sea) (Arthi and Shanmugam, 2012 and references therein). Some of the observed surface algal bloom distributions were consistent with our ship observations and earlier surveys conducted in Arabian Sea waters and coastal waters on the southeast coast of India. Through the use of OSABI data, the location, extent, intensity, seasonal and interannual variability of various surface algal bloom events investigated in this study extend our current understanding of their occurrences and dynamics. Our findings further show spatially extensive blooms in the Arabina Sea, with their maximum intensity and aerial coverage in winter. Expansion and spreading of these blooms are mainly caused by the prevailing currents and favorable environmental conditions in winter. The time series OSABI data also indicate an increase in their extent and retention period in the recent years. New growth and distributions of such blooms along the southern coastal areas of India pose a major concern for coastal managers, who are actively involved in various developmental activities in these regions. In addition to a strong association between the seasonal cycles of surface algal blooms and the seasonal cycles of physical oceanographic and aerosol patterns, the recent sea 
level rise, climate oscillations and changes in environmental conditions may have profound impacts on the recent trends of these blooms in coastal and oceanic waters around India. Thus, our findings will have an immediate and important bearing on fisheries, primary productivity, coastal development activities and climate change.

\section{Acknowledgments}

This work was supported by INCOIS under the grant (OEC/13-14/117/INCO/PSHA) of the SATCORE program. We gratefully acknowledge the NASA Ocean Biology Processing Group for making available the LAC MODIS-Aqua data to this study. We also gratefully acknowledge the National Climatic Data Center of NOAA for wind data and the AVISO for sea surface height data.

\section{References}

Alvarinho, J.L., \& Hiroshi, K. (2004). Air-Sea Interaction, Coastal circulation and primary production in the eastern Arabian Sea: A review. Journal of Oceanography, 60, 205-208.

Arthi, S., \& Shanmugam, P. (2012). An algorithm for Classification of algal blooms using MODISAqua data in Oceanic waters around India. Advances in Remote Sensing, 1 35-51.

Gomes, H.R., Goes, J.I., Prabhu Matondkar, S.G., Sushma, G.P., Adnan, R.N., Al-Azri Prasad, G., \& Thoppil, G. (2008). Blooms of Noctiluca Milliaris in the Arabian Sea-an in situ and satellite. Deep-Sea Research, 55, 751-65.

Goes, J.I., Thoppil, P,G., Gomes, H.R., \& Fasullo, J.T. (2005). Warming of the Eurasian landmass Is making the Arabian Sea more productive. Science, 308, 545-47.

$\mathrm{Hu}, \mathrm{C}$. (2009). A novel ocean color index to detect floating algae in the global oceans. Remote Sensing of Environment, 113, 2118-2129.

Li, L., Li, L, Song, K., Li ,Y., Shi, K., \& Li Z 2011 An improved analytical algorithm for remote estimation of chlorophyll-a in highly turbid waters Environ. Res. Lett. 6 doi:10.1088/17489326/6/3/034037.

Morrison, J.M., Codispoti, L.A., Gaurin, S., Jones, B., Manghnani, V., \& Zheng, Z. (1998). Seasonal variation of hydrographic and nutrient fields during the US JGOFS Arabian Sea process study. Deep Sea Research. 45. 2053- 101.

Olson, D.B., \& Morrison, J.M. (1992). Seasonal basin wide extremes in T-S characteristics in the near surface waters of the Arabian Sea and Somali basin Oceanography of the Indian Ocean. Oxford and IBH Publishing Co. Ltd, New Delhi, 605-16.

Prasanna Kumar, S., Roshini, R.P., Narvekar, J., Dinesh Kumar, P.K., \& Vivekanandan, E. (2010). What drives the increased phytoplankton biomass in the Arabian Sea?. Current Science, 99, 101106. 
Sarangi, R.K., Chauhan, P., \& Nayak, S.R. (2004). Detection and monitoring of Trichodesmium blooms in the coastal waters off Saurashtra coast, India using IRS-P4 OCM data. Current Science, 86, 1636-1641.

Shanmugam, P. (2011). A new bio-optical algorithm for the remote sensing of algal blooms in complex ocean waters. Journal of Geophysical Research, 116, C04016 doi:10.1029/2010JC006796.

Shanmugam, P., Suresh, M., \& Sundarabalan, V.B. (2013). OSABT An innovative algorithm to detect and characterize surface algal blooms. IEEE Transaction on Selected Topics in Earth Observations and Remote Sensing, 6, 1879-1892.

Shankar, D., Vinayachandran, P.N., \& Unnikrishnan, A.S. (2001). The monsoon currents in the north Indian Ocean. Progress in Oceanography, 52, 63-120.

Steckbauer, A., Duarte, C.M., Carstensen, J., Vaquer-Sunyer, R., \& Conley, D.J. (2011). Ecosystem impacts of hypoxia: thresholds of hypoxia and pathways to recovery. Environ. Res. Lett., 6, doi:10.1088/1748-9326/6/2/025003.

Takeuchi, N. (2013). Seasonal and altitudinal variations in snow algal communities on an Alaskan glacier (Gulkana glacier in the Alaska range). Environ. Res. Lett., 8, doi:10.1088/17489326/8/3/035002.

Vinayachandran, P.N., Chauhan, P., Mohan, M., \& Nayak, S. (2003). Biological response of the sea around Sri Lanka to summer monsoon. Geophysical Research Letters, 31, L01302 doi:10.1029/2003GL018533.

Vinayachandran, P.N., \& Mathew, S. (2003). Phytoplankton bloom in the Bay of Bengal during the northeast monsoon and its intensification by cyclones. Geophysical Research Letters, 30, 1572, doi:10.1029/2002GL016717. 

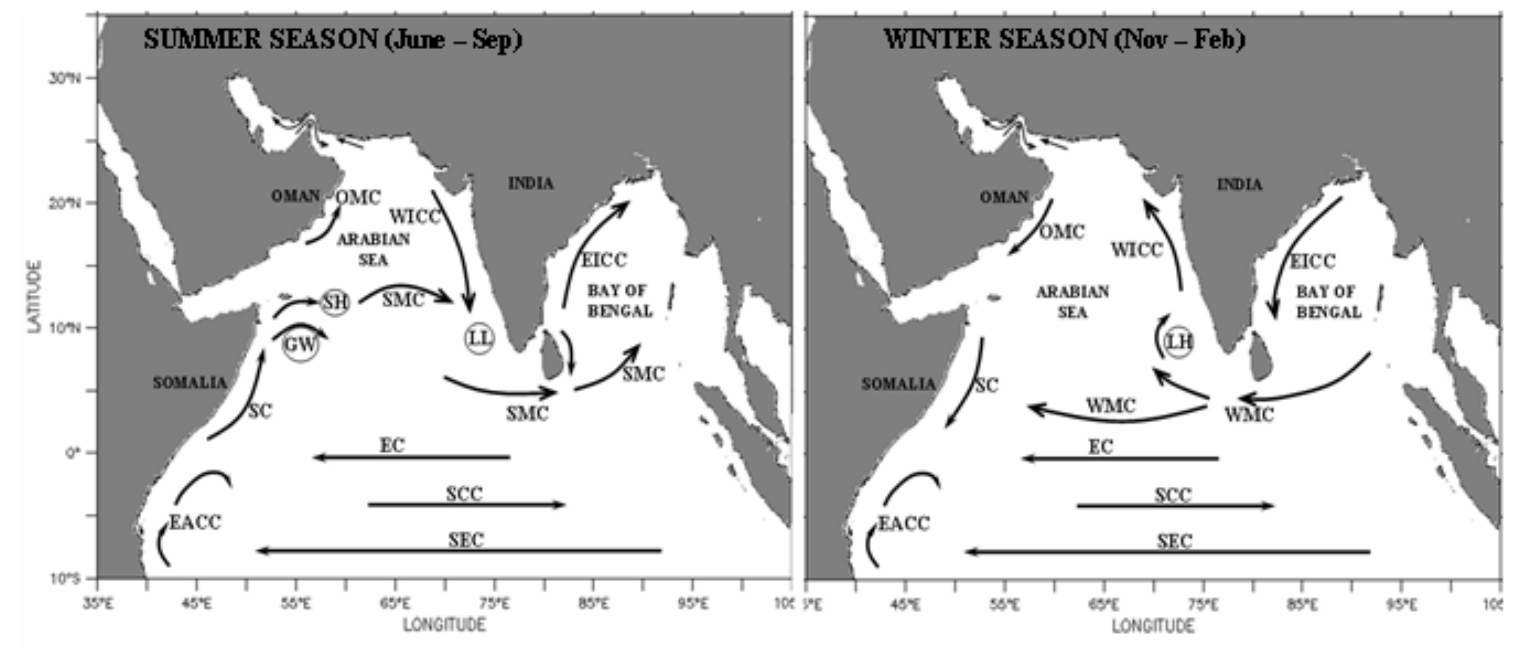

Fig. 1. Map of the study area depicting major currents in the Arabian Sea, Indian Ocean and Bay of Bengal during summer (June-September) and winter (November-February). Abbreviation are as follows: Somali current (SC), Equatorial current (EC), South Equatorial Counter current (SCC), Winter monsoon current (WMC), West India coastal current (WICC), East India coastal current (EICC), East African coastal current (EACC), South Equatorial current (SEC), Lakshadweep high (LH), Oman coastal current (OMC), Great whirl (GW), Socotra high (SH), Summer Monsoon current (SMC), Lakshadweep low (LL). These current patterns are redrawn from Alvarinho et al. (2004) and Shankar et al. (2001). 

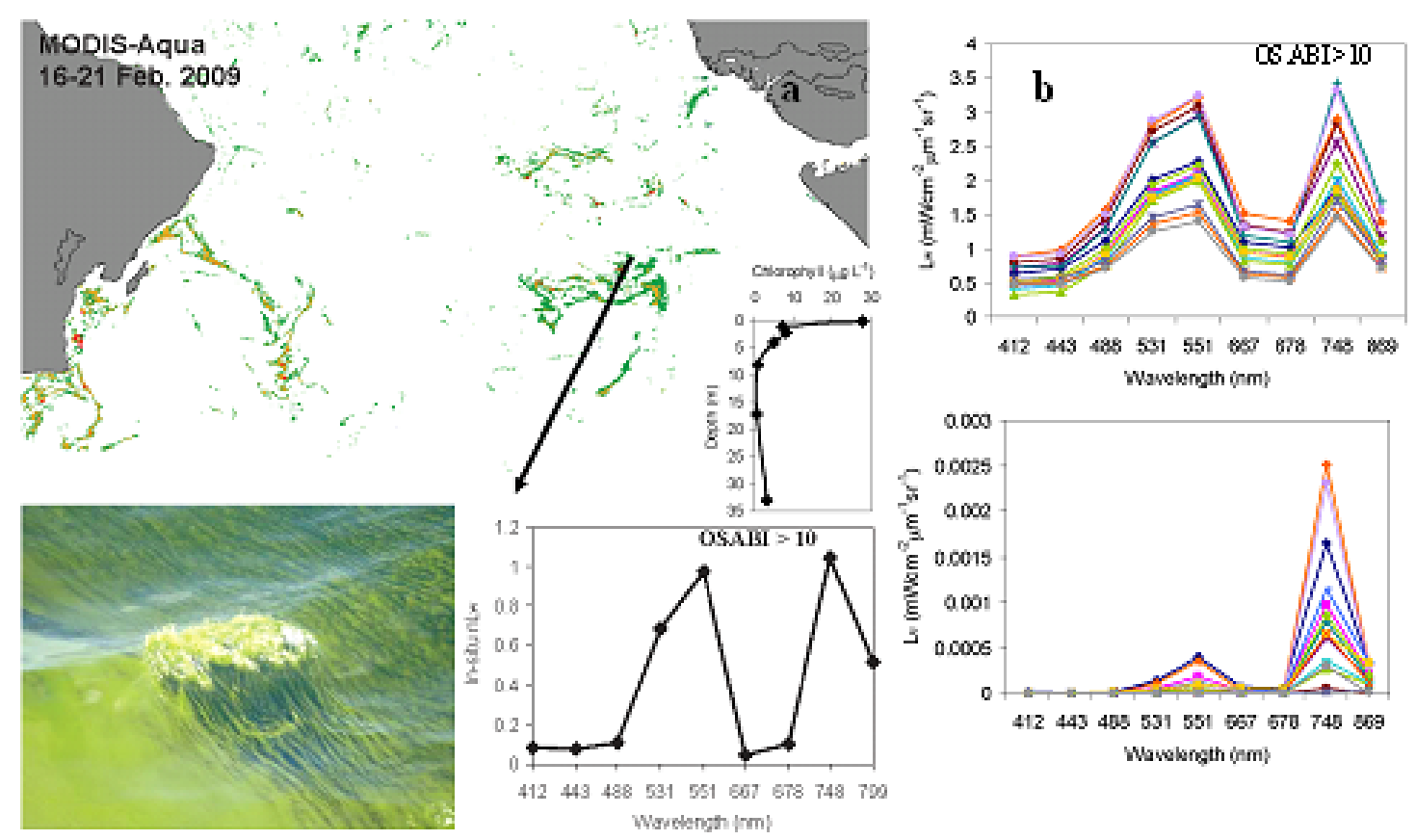

Fig. 2a. A MODIS-Aqua OSABI image along with in-situ observations of Noctiluca bloom (see the field photo, vertical distribution of Chl-a concentration and normalized water-leaving radiance from a point measurement) in the Arabian Sea. (b) The surface-leaving radiances measured from a boat (using the above-water Trios radiometers) and upwelling radiances just below the water surface (using the underwater Trios radiometers) from several locations in the lagoon on the southeast coast of India. 


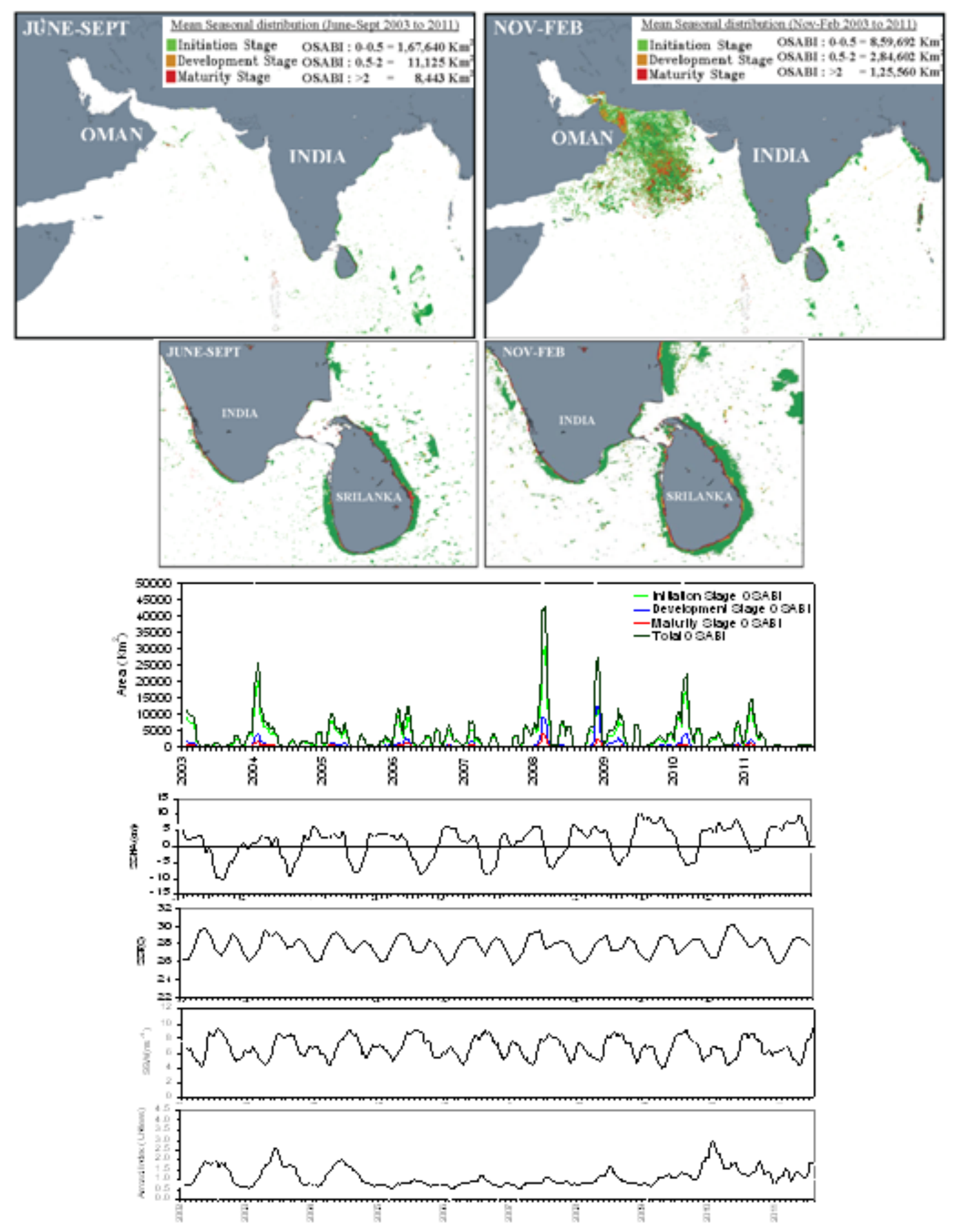

Fig. 3. Seasonal composite OSABI images derived from MODIS-Aqua for the period 2003-2011 (top panels). Time series plots of the aerial coverage of the different stages (initial, development and maturity) of the surface algal blooms, sea surface height anomaly (SSHA), sea surface temperature (SST), sea surface wind (SSW) and aerosol index (bottom panels) for the period 2002-2011. 

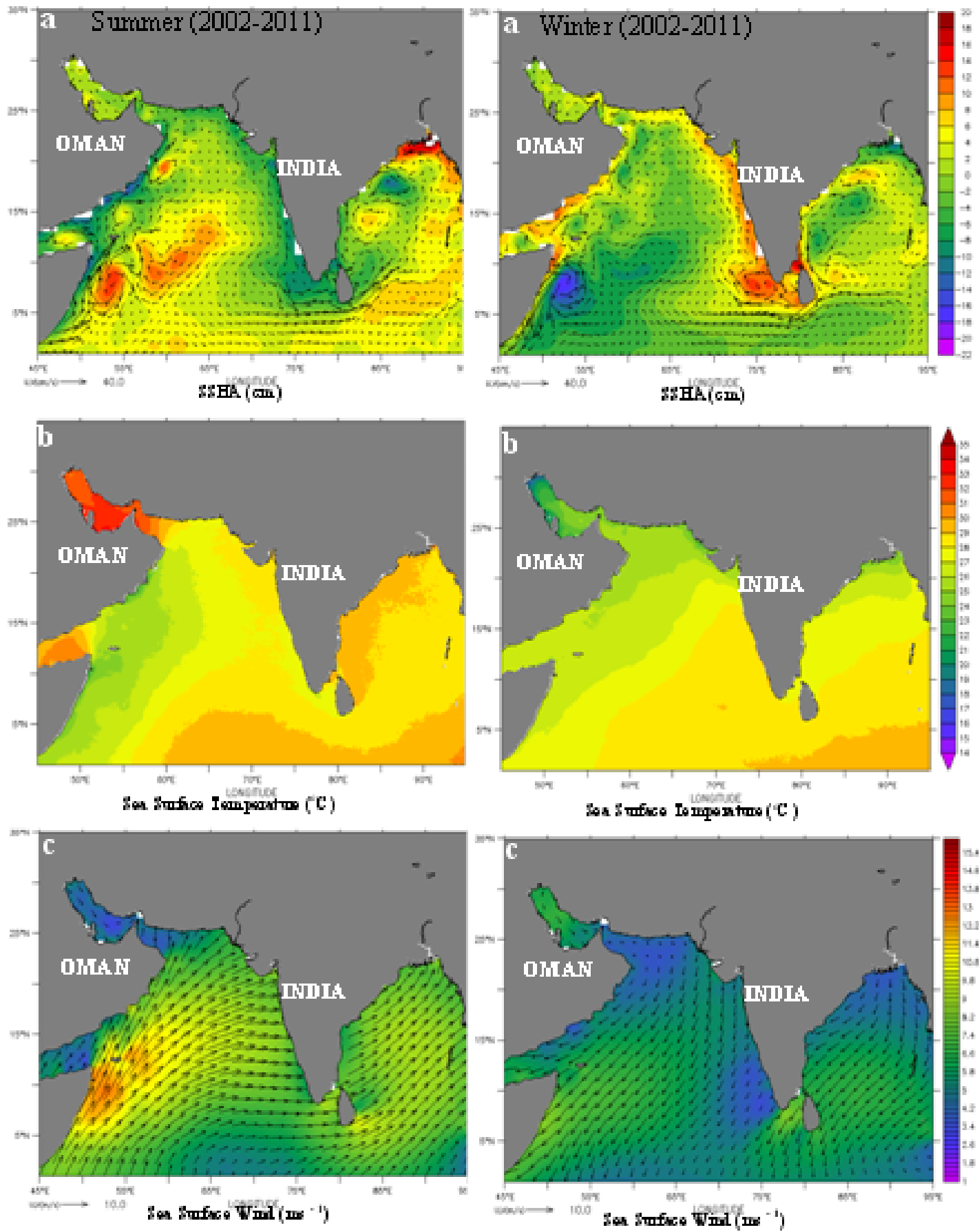

Fig. 4. Mean seasonal images (Left panels: June to September; Right panels: November to February for the years 2003-2011) of (a) sea surface height anomaly (SSHA in cm) and geostrophic currents from multi-satellite altimeters, (b) Sea surface temperature from MODIS-Terra, and (c) wind direction and speed from NOAA-Seawinds. 